\title{
Development Trend Analysis of Voluntourism in Hubei China
}

\author{
Xinfa Tang ${ }^{1, a}$, Yujia $\mathrm{Gu}^{2, \mathrm{~b}}$ \\ ${ }^{1}$ Tourism College, Jiangxi Science \& Technology Normal University, Nanchang, China \\ ${ }^{2}$ International Hotel Class in Tourism Management of Grade 2012, Tourism College, Jiangxi \\ Science \& Technology Normal University, Nanchang, China \\ a xinfatang@sina.com.cn, b24999768@qq.com
}

Keywords: Volunteer tourism, Development, Tourism Management, Hubei Province

\begin{abstract}
With the changes of the times, the competition of tourism industry is becoming more and more intense. Because the speed of development of China's volunteer tourism is slow, the space of it is relatively large. So it is very important to make a reasonable analysis of the development of volunteer tourism in our country. This article takes the Hubei volunteer tourism as the breakthrough point, and analyzes the development tendency, the development superiority and the restriction factor, then puts forward some feasible countermeasures and suggestions to its development.
\end{abstract}

\section{Introduction}

Voluntourism is referred to as the voluntary access of individual to some particular group free of charge, completing certain activity or help some object while traveling, namely undertaking corresponding responsibilities while enjoying the travel experience. The analysis of the current circumstance of voluntourism development is made in this paper. Taking the voluntourism in Hubei Province as an entry point, the developing trend, developing advantages and constraints concerning the voluntourism in Hubei is analyzed in great detail. Additionally, countermeasures and suggestions on the development of voluntourism are raised in this paper.

\section{Analysis on the current situation of the development of voluntourism in Hubei Province}

\subsection{Advantages of the development of voluntourism in Hubei Province}

The mountainous area accounts for about $50 \%$ of the Hubei Province, and there are twenty-eight state-level poverty counties and three provincial poverty counties. The general voluntourist destination is mainly mountainous area. Meanwhile, food, traveling, shopping and entertainment are involved in the process of voluntourist activities, which can lead to certain economic development. During the process of the development of voluntourism in Hubei Province, the specific advantages are summarized in the following four aspects due to the impact of national policies or the influence of various reasons.

\subsubsection{The great education foundation of Hubei Province}

Education on the role of the tourism industry is huge, and a good educational foundation is an important driving force for the development of voluntourism. Hubei Province is a famous province for education of China, University Resources in Wuhan ranked third in the China, only behind Beijing and Shanghai. We can know that a total of 154 of the Ministry of education to recognize the degree of full-time university, which has 10 key university in Wuhan. This shows that Hubei's educational resources are very rich. On the premise of the gradual development of tourism, many colleges and universities have set up the professional courses, so that the concept of tourism of 
young people to be updated. And due to the continuous progress of China, more and more people meet "who have time and money" this condition among young people. Comprehensive view of these two points, the Hubei education foundation for voluntourism in Hubei Province has a role in promoting.

On the other hand, the public service will provide some opportunities for development, but also can provide the economic rise space, and the voluntourism will have a certain role in the cause of voluntourism destination. If seriously pay attention to public service, this aspect of the economy and education in Hubei Province is a certain way to improve.

\subsubsection{Convenient network led to the rapid spread of the information}

In recent years, the network has been getting increasingly popular and has entered almost everyone's life. Thanks to its convenient, safe, all-round and free traits, people are allowed to get a wide variety of information at all times and places. There are more and more resources of network platform in the result of the development of technology and living standard. In terms of voluntourism, tourists can get more relevant information; for public organizations, they can use websites, forums or posts to attract more attention; for social media, they may call for more social attention to public welfare undertakings; for enterprises, they may follow public welfare undertakings more easily. From this view, people of other provinces may get more and more information on public welfare undertakings of Hubei Province on Internet, which benefits the development of its voluntourism.

\subsubsection{Hubei Province has rich tourism resources}

Hubei Province is very rich in tourism resources, different regions have different characteristics of tourism resources. On the one hand, it has a large number of natural landscapes. On the other hand, it is a profound cultural heritage with a large number of historical monuments in Hubei Province. The Emperor Yan was born in Hubei Province, and Hubei has an unique culture. Rich tourism resources will attract many local or foreign tourists, so it can increase the source of tourists, enhance the visibility. The bigger number of the tourists is, the more visitors who join to voluntourism are. In addition, people who attend to voluntourism can also view other beautiful tourist attractions of Hubei Province additionally. So it is great for both sides.

\subsubsection{Convenient traffic conditions in Hubei Province}

Tourist traffic is an important part of travel, it refers to the tourists in different ways or methods, implementation from one region to another region. For tourists, the choice of the mode of transport and roads whether level off will affect tourists intuitive feelings and mood, so the traffic conditions are in good condition to a large extent affected the feelings of the whole process of tourism. Hubei Province is known as its "thorough fares of nine provinces", very convenient traffic conditions. In 2014, Hubei Province transportation spent more than one hundred billion yuan, ranked third in China. Hubei Province has built for rural highway 14000 km, 5106 km highway traffic mileage, Wuhan increased Moscow, San Francisco and other six international routes, international and regional routes of article 31 directly. On the convenient transportation conditions, these conditions increase the public welfare initiative of tourists and freedom, they will also improve the satisfaction of the travel process. From a long-term perspective, it is a big advantage for Hubei Province's voluntourism that Hubei Province has such convenient traffic conditions.

\subsection{The restriction factors of public tourism development in Hubei Province}

Hubei Province public welfare foundation in view of traffic or tourism development has certain advantages, Summarized as the four followings. 


\subsubsection{The notion of limited popularity}

Voluntourism as a new concept, popular in the developed areas or young people, but the concept is different from traditional tourism mode, it is not accepted by most people. In terms of Hubei Province, we can find some information through searching the Internet. The travel in Wuhan, including volunteer team in the formal organization of public travel, only Kang Hui travel involves public travel. And similar website hits is no more than thousands, we can know that this kind of activities influence is not big, and driving force is lesser. And Hubei Province has not many of the activities of public travel information, the activities of public travel were most recommended by their experience through BBS or other means, and the website were even filled with false information of fishing, so the concept is not particularly popular.

\subsubsection{Lack of policy support}

If an activity or enterprise can get government policy support, this will be a very important promoting measures. On the policy of Hubei Province's volunteer tourism, we can only search about "through the development of tourism to promote poverty", the true sense of the propulsion of public travel policy is not exist on the Internet. It seems that Hubei Province's volunteer travel activities lack the government's policy support.

\subsubsection{Financial support is not strong enough}

For the sustainable development of the tourism industry, the attitude of the tourists, the tourism industry's investment funds and a steady stream of tourists are very important conditions ${ }^{[1]}$. The current volunteer travel agencies lack of powerful guarantee fund. In the case of public travel network in China, the income is mainly used to pay the villagers reception, commissions, transportation and insurance. Reception costs accounted for $70 \%$ of the total cost, the project commission accounted for $10 \%$, transportation and insurance costs accounted for $10 \%$. The development of the family hotel, the route design of voluntourism's destination, the local reception farmers and guide (mainly local residents) personnel training, are not a trivial matter for budget, it's absolutely not enough to expect to extract money ${ }^{[2]}$.

\subsubsection{Volunteer tourism organization competitiveness is not strong}

At first, because of the liquidity of current mainland's volunteer organizations, the volunteer will leave their companies, or exit every two years. The main reason is that most of the staff's income are relatively lower and lower; life pressure, social pressure(about parents, classmates, colleagues, etc.) are bigger and bigger. From the staff, as we know, volunteers can't obtain money and they have to pay more and more to get the spirit of their joy. Imagine this situation that how many capital enterprises are willing to invest, how many people are willing to enter. On the public investment returns, it is not only money, but also can improve the environment that live in. Beneficiary beneficiary is the person, perhaps no personal benefits. For now, in Hubei Province, the total number of all youth volunteer association is more than 3000, more than 2 million people registered volunteers, but liquidity is very big. It is worth to be a further development for the development of voluntourism.

\section{The countermeasures of voluntourism's development in Hubei Province}

Although the voluntourism in Hubei Province got some achievements in the past a period of time, but it still has many deficiencies in recent year. To implement the sustainable development view, the development of voluntourism in Hubei Province should pay more attention to the following three aspects. 


\subsection{Improve the influence of voluntourism in Hubei Province}

In order to improve voluntourism in Hubei Province, improving its influence is one of the important measures. Government departments can play a guiding role, the social from all walks of life can increase the propaganda. We could promote voluntourism to combined with the government and commercial enterprises better, to form the benign development. For example, there are many universities and students in Hubei Province. We can organize the Hubei youth volunteers, and lead the students to develop all kinds of public welfare activities, to enhance the influence of voluntourism in the Hubei Province's tourism industry.

\subsection{Develop more forms of voluntourism}

In order to develop the sustainability of voluntourism in Hubei Province, it will not lack of products to attract passengers. If we can develop more forms of public travel, Hubei Province public tourism destination will become the class of all ages travel personage, and this can from different themes and lines to consider. For example, we can choose line associated with the theme of the nature for teens. For people with a certain cultural quality, we can choose to religion, support this aspect consideration. For elderly tourists, we can from the homing, feedback point of view to consider. At the same time, we also need to combined the situation of Hubei Province and policy to do this.

\subsection{The government should formulate the policies and regulations}

According to the concept of public travel, if it lacks of the government's policy support, it is difficult to develop long and firm. Thus, if you want to further development in Hubei Province's voluntourism, it certainly cannot lack of government guidance and support. But on the current situation, the government has made a certain measure. For example, on September 28, 2015, the Wuhan tourism volunteer service group was founded. And on October 1, the first batch of China's tourism volunteers in the official start of the duty. Wuhan is the first city which starts tourism volunteer service, and now there are more than 1000 people officially registered volunteers. Therefore, in order to make better public tourism development of Hubei Province, Hubei provincial government also need to continue to launch the feasible policies and solutions.

\section{Conclusion}

Although Chinese voluntourism is in primary development stage and its investigation and practice is laggard, "voluntourism" is the innovation of mode. It extends and boldly tries public welfare nature in tourism industry. The categorization research and specific implement of voluntourism helps further development of Hubei tourism market, and subsidizes the development of Hubei voluntourism. When exploring development laws of Chinese voluntourism, China should refer to development processes of other countries, fully analyzes advantages and disadvantages of development of domestic voluntourism, and drive diverse and individualized development of voluntourism.

\section{References}

[1] ZongYuanYuan, Public tourism motivation, experience and influence research review [J]. Journal of tourism science, 2012, 01:78-94

[2] Zong YuanYuan. Europe and the United States public tourism research [J]. Journal of sichuan normal university (social science edition), 2010,01:133-140 